\title{
Correlates of Total and domain-specific Sedentary behavior: a cross-sectional study in Dutch adults
}

Esmée A. Bakker ${ }^{1,2}$, Maria T. E. Hopman ${ }^{1}$, Duck-chul Lee ${ }^{3}$, André L. M. Verbeek ${ }^{4}$, Dick H. J. Thijssen ${ }^{1,2}$ and Thijs M. H. Eijsvogels ${ }^{1 *}$

\begin{abstract}
Background: Sedentary behavior (SB) is associated with increased risks of detrimental health outcomes. Few studies have explored correlates of SB in physically active individuals. Furthermore, SB correlates may depend on settings of SB, such as occupation, transportation and leisure time sitting. This study aims to identify subject-, lifestyle- and health-related correlates for total SB and different SB domains: transportation, occupation, and leisure time.

Methods: Dutch participants were recruited between June, 2015 and December, 2016. Participant characteristics (i.e. age, sex, weight, height, marital status, education level, employment), lifestyle (sleep, smoking, alcohol consumption, physical activity) and medical history were collected via an online questionnaire. SB was assessed using the Sedentary Behavior Questionnaire and estimated for 9 different activities during weekdays and weekend days. Logistic regression was used to calculate odds ratios and $95 \%$ confidence intervals for the association between correlates and SB. Total SB was dichotomized at $>8 \mathrm{~h} /$ day and $>10 \mathrm{~h} /$ day, and being sedentary during transportation, occupation and leisure time at the 75th percentile (60 min/day, $275 \mathrm{~min} /$ day and $410 \mathrm{~min} /$ day, respectively).
\end{abstract}

Results: In total, 8471 participants (median age 55, 55\% men) were included of whom 86\% met the physical activity guidelines. Median SB was $9.1 \mathrm{~h} /$ day $\left(\mathrm{Q}_{25} 6.3-\mathrm{Q}_{75} 12.0\right)$ during weekdays and $7.4 \mathrm{~h} /$ day $\left(\mathrm{Q}_{25} 5.5-\mathrm{Q}_{75} 9.5\right)$ during weekend days. SB was most prevalent during leisure time $\left(5.3 \mathrm{~h} /\right.$ day; $\mathrm{Q}_{25}$ 3.9- $\mathrm{Q}_{75}$ 6.8), followed by occupation ( $2 \mathrm{~h} /$ day; $\mathrm{Q}_{25}$ 0.1- $\left.\mathrm{Q}_{75} 4.6\right)$ and transportation ( $0.5 \mathrm{~h} /$ day; $\mathrm{Q}_{25} 0.2-\mathrm{Q}_{75}$ 1.0). Younger age, male sex, being unmarried, higher education, employment and higher BMI were significantly related to higher levels of total SB. Younger age, male sex, employment, and higher BMI increased the odds for high SB volumes during occupation and transportation. Higher education, being unmarried and smoking status were positively associated with high volumes of occupational SB only, whereas older age, being unmarried, unemployment, higher BMI and poor health were positively linked to leisure time SB.

Conclusions: SB is highly prevalent in physically active individuals, with SB during leisure time as the most important contributor. Correlates for high volumes of SB vary substantially across SB domains, emphasizing the difficulty to target this unhealthy lifestyle.

Keywords: Sedentary behavior, Sitting time, Physical activity, Self-report, Cardiovascular diseases, Healthy lifestyle

\footnotetext{
* Correspondence: Thijs.Eijsvogels@radboudumc.nl

${ }^{1}$ Department of Physiology, Radboud Institute for Health Sciences, Radboud

University Medical Center, P.O. Box 9101, 6500, HB, Nijmegen, The

Netherlands

Full list of author information is available at the end of the article
}

(c) The Author(s). 2020 Open Access This article is distributed under the terms of the Creative Commons Attribution 4.0 International License (http://creativecommons.org/licenses/by/4.0/), which permits unrestricted use, distribution, and reproduction in any medium, provided you give appropriate credit to the original author(s) and the source, provide a link to the Creative Commons license, and indicate if changes were made. The Creative Commons Public Domain Dedication waiver (http://creativecommons.org/publicdomain/zero/1.0/) applies to the data made available in this article, unless otherwise stated. 


\section{Background}

Physical inactivity importantly contributes to the development of non-communicable diseases, such as cardiovascular diseases (CVD), type 2 diabetes, and breast and colon cancer [1]. In addition, evidence for deleterious health effects of sedentary behavior is rapidly accumulating. SB includes any waking behavior characterized by an energy expenditure $\leq 1.5$ METs while in a sitting or reclining posture [2-4]. For example, sedentariness is associated with increased risks for all-cause mortality and the incidence of CVD, cancer, and type 2 diabetes $[5,6]$. These observations emphasize the importance of $\mathrm{SB}$ as a highly prevalent, independent and modifiable risk factor for all-cause mortality and non-communicable diseases.

To enable effective reductions in SB via interventions or public health campaigns [7], identification of SB correlates is needed. A recent systemic review suggested that age, body mass index (BMI), physical activity levels, mood and attitude were associated with sedentariness [8]. However, identification of these correlates is primarily based on the general population, largely consisting of individuals not meeting the recommended physical activity guidelines. Previous work found physical activity could attenuate the adverse effects of sedentary behavior, but this was only present in individuals performing > 35.5 MET-hours/week (60-75 min of moderate intensity activity per day) [9]. Therefore, higher levels of sedentary behavior may have deleterious health effects in physically active individuals performing < 35.5 MET-hours/week. Correlates related to sedentary behavior may differ between physically inactive versus active individuals. Furthermore, SB correlates may depend on settings of $\mathrm{SB}$, such as occupation, transportation and leisure time sitting $[8,10]$. Better understanding of correlates of sedentary time, but also its dependency on the specific domains of SB, is needed to develop and implement interventions targeting SB.

We explored correlates of sedentary time in relation to the different settings of occupation, transportation, leisure time in a population with a wide range of physical activity levels. We hypothesized that subject-, lifestyleand health-related correlates, such as identified in previous studies in the general population, also relate to SB in a physically active population. However, we expected that the presence and magnitude of these associations would be different across SB domains.

\section{Methods}

\section{Study population}

The Nijmegen Exercise Study is based on a cohort of individuals participating in Dutch sport events (i.e. International Nijmegen Four Days Marches and the Seven Hills Run) and their family and friends. The Nijmegen Exercise Study aims to investigate the impact of physical activity on health. Online questionnaires were used to inquire participants about demographic characteristics, anthropometric measures, lifestyle factors, and health status. All Dutch-speaking adults were eligible for the study. Participants were recruited via newsletters and internet advertisements between June 1, 2015 and December 31, 2016. A total number of 8952 participants completed the online questionnaire. After exclusion of participants with missing data for date of birth $(n=2)$ and sex $(n=1)$, or women who were pregnant $(n=45)$, 8904 participants remained available for inclusion. Another 433 participants were excluded for insufficient completion of the SB questionnaire, which resulted in 8471 participants being eligible for statistical analyses. The study (NL36743.091.11) was approved by The Local Committee on Research Involving Human Subjects of the region Arnhem and Nijmegen, the Netherlands. All participants provided written informed consent.

\section{Questionnaire}

The online questionnaire asked participants about general characteristics, lifestyle factors and their medical history. General characteristics contained age, sex, weight, height, marital status, level of education and employment status. Lifestyle factors included sleeping hours, smoking behavior, alcohol consumption, and habitual physical activity. Smoking status was categorized into individuals who never smoked, smoked in the past (former smokers), and currently smoking. Heavy alcohol drinking was defined as $>14$ alcoholic drinks per week for men, and $>7$ for women [11]. Physical activity was measured with the SQUASH questionnaire [12]. Weekly physical activity was converted into METs and multiplied by minutes per week. MET minutes per week were classified into four categories: inactive $(0$ MET min/week), insufficient (1-499 MET min/week), medium (500-999 MET min/week), and high ( $\geq 1000$ MET min/week) based on the 2018 US Physical Activity Guidelines [13]. In addition, participants were asked to subjectively describe their health status (very good, good, reasonable, fair, poor), and whether they had a physician confirmed diagnosis of CVD (myocardial infarction, stroke, or heart failure), cancer, or cardiovascular risk factors (hypertension, hypercholesterolemia, or diabetes mellitus).

\section{Assessment of sedentary behavior}

Sedentary time was assessed using the Sedentary Behavior Questionnaire [14]. Sedentary time was estimated for nine different activities: watching television, playing computer/ video games, sitting during eating and drinking, sitting while listening to music, sitting and talking on the phone, doing paperwork or office work, sitting and reading, sitting and playing a musical instrument or doing arts and crafts, sitting and driving/riding in a car, bus, or train. The nine items were completed for weekdays and weekend days separately, and stratified into three domains (occupation, 
transportation and leisure time). Sitting during occupation consisted of doing paperwork or office work; sedentary time during transportation contained sitting and driving/riding in a car, bus, or train; and leisure time sitting consisted of watching television, playing computer/video games and sitting during eating and drinking, sitting while listening to music, sitting and talking on the phone, sitting during reading, and sitting during playing a musical instrument or doing arts and crafts. Total sedentary behavior was based on the sum of the nine items per weekday and weekend day. The average amount of sedentary time per day was calculated by multiplying weekdays estimates by 5 and weekend days estimates by 2 and dividing this by 7 . Since there are no thresholds for high engagement in sedentary time, we defined a high amount of sedentary time as $>8 \mathrm{~h} /$ day and $>10 \mathrm{~h}$ /day based on previous literature [15-17]. High amount of sedentary time during transportation, occupation and leisure time sitting were based on the $75 \%$ percentile (i.e. $1 \mathrm{~h} /$ day, $4 \mathrm{~h}$ and $25 \mathrm{~min} /$ day, and $6 \mathrm{~h} 50 \mathrm{~min} /$ day, respectively). Individuals, who were unemployed or retired, were excluded from the analyses regarding high levels of occupational sedentary time.

\section{Statistical analysis}

Baseline characteristics were summarized as mean and SD or median and interquartile range for continuous variables, and as number and percentage for categorical variables. Associations with age, sex, marital status, education level, employment, BMI, smoking status, heavy alcohol drinking, physical activity and disease history were tested separately for total sedentary time and each setting of sedentary time using multivariable logistic regression analysis. We performed a complete case analysis $(n=7648)$, and analysis using multiple imputation $(n=8471)$ because $10 \%(n=823)$ of the cases had missing values for one or more correlates. Missing data was imputed with multivariable imputation by chained equations with predictive mean matching. We checked patterns of missing data and followed the 'missing at random' assumption. All available variables were used to predict missing values in 10 imputed datasets with 100 burn-in iterations. Healthy convergence, imputed distribution and plausibility were verified. Furthermore, pooled estimates were derived from the 10 imputed datasets.

In addition, we analyzed the association of the previously mentioned correlates with continuous hours of total sedentary time and domains-specific sedentary time using multivariable linear regression analysis. Since sedentary time had a skewed distribution, we transformed sedentary time with the natural logarithm. Furthermore, we performed stratified analyses for active (MET min/ week 2500 ) and inactive (MET min/week < 500) individuals. All statistical tests were 2-sided, and significance was set at $P<.05$. All analyses were performed using SAS statistical software, version 9.4 (SAS Institute).

\section{Results}

\section{Study population}

The study population had a median age of 55 years $\left(\mathrm{Q}_{25}\right.$ $45, \mathrm{Q}_{75} 64$ ) and $55 \%$ were men (Table 1 ). The majority of the participants were married (79\%), received higher or academic education (62\%) and were employed (75\%). Two thirds of the participants had normal weight (66\%), more than half never smoked (54\%). As intended for the purpose of this research, $86 \%$ of the participants met the 2018 US Physical Activity Guidelines [13]. The majority of the study population (90\%) classified their health status as good or very good. In total, $7 \%$ of the participants had a history of CVD, $16 \%$ hypertension, $13 \%$ hypercholesterolemia, $4 \%$ diabetes mellitus, and $8 \%$ cancer.

\section{Prevalence of sedentary behavior}

Participants reported a median sedentary time of $9.1 \mathrm{~h}$ $\left(\mathrm{Q}_{25}\right.$ 6.3, $\mathrm{Q}_{75}$ 12.0) during weekdays and a median of 7.4 h $\left(\mathrm{Q}_{25} 5.5, \mathrm{Q}_{75}\right.$ 9.5) during weekend days. Sedentary time significantly differed across settings between weekdays and weekend days $(P<.05)$. Median sedentary time at work was $2 \mathrm{~h} /$ day $\left(\mathrm{Q}_{25} 0.1, \mathrm{Q}_{75}\right.$ 6.0) on weekdays and $0 \mathrm{~h} /$ day $\left(\mathrm{Q}_{25} 0, \mathrm{Q}_{75} 0.4\right)$ on weekend days. Median sedentary time during transportation was $0.4 \mathrm{~h} /$ day $\left(\mathrm{Q}_{25} \quad 0.1, \mathrm{Q}_{75} \quad 1.0\right)$ on both weekdays and weekend days. Sedentary time during leisure time was $4.8 \mathrm{~h} /$ day $\left(\mathrm{Q}_{25} 3.5, \mathrm{Q}_{75} 6.4\right)$ on weekdays and $6.25 \mathrm{~h} /$ day $\left(\mathrm{Q}_{25} 4.6, \mathrm{Q}_{75}\right.$ 8.1) on weekend days. The prevalence of domain specific sedentary time, physical activity and sleeping time differed significantly between age categories ( $p$-value Kruskal-Wallis $<0.001$, Fig. 1).

\section{Correlates of sedentary behavior}

Younger age was significantly associated with higher odds of total sedentary time for $\geq 8$ and $\geq 10 \mathrm{~h} /$ day, sedentary time during transportation and sedentary time at work (Figs. 2 and 3, and Table 2). This association reversed for sedentary time during leisure time, where we found that older age was associated with higher levels of sedentary time. Male sex was positively associated for all types of sedentary time, except for sedentary time during leisure time. Being unmarried was associated with higher levels of total amount of sedentary time and during transportation and occupation. Higher education was positively associated with total sedentary time and sedentary time at work, but not during transportation and leisure time.

BMI showed a clear positive association with higher levels of sedentary time for all domains, where the odds increased with higher BMI categories. Physical activity and smoking status were the only lifestyle factors that were significantly associated with sedentary time. Higher levels of physical activity increased the odds of total 
Table 1 General Characteristics of the 8471 Participants

\begin{tabular}{|c|c|c|}
\hline Characteristic & & Number of missing data \\
\hline \multicolumn{3}{|l|}{ Subject } \\
\hline Age & $55(45-64)$ & 0 \\
\hline Sex (male) & $4629(55 \%)$ & 0 \\
\hline Marital status (married or registered partnership) & $6652(79 \%)$ & 43 \\
\hline Education & & 58 \\
\hline Low & $687(8 \%)$ & \\
\hline Intermediate & $2526(30 \%)$ & \\
\hline High/academic & $5200(62 \%)$ & \\
\hline Employment (yes) & $6320(75 \%)$ & 43 \\
\hline $\mathrm{BMI}\left(\mathrm{kg} / \mathrm{m}^{2}\right)$ & & 45 \\
\hline Normal weight $\left(<25 \mathrm{~kg} / \mathrm{m}^{2}\right)$ & $5594(66 \%)$ & \\
\hline Overweight $\left(25-29 \mathrm{~kg} / \mathrm{m}^{2}\right)$ & $2432(29 \%)$ & \\
\hline Obesity $\left(\geq 30 \mathrm{~kg} / \mathrm{m}^{2}\right)$ & $400(5 \%)$ & \\
\hline \multicolumn{3}{|l|}{ Lifestyle } \\
\hline Smoking status & & 48 \\
\hline Never smoker & $4510(54 \%)$ & \\
\hline Previous smoker & $3436(41 \%)$ & \\
\hline Current smoker & $477(6 \%)$ & \\
\hline Heavy alcohol drinking (yes) & $1544(19 \%)$ & 154 \\
\hline Sleeping hours per day & $7.0(6.5-8.0)$ & 358 \\
\hline Physical activity guidelines & & 0 \\
\hline 0 MET-min/week & $3(0 \%)$ & \\
\hline 1-499 MET-min/week & $1162(14 \%)$ & \\
\hline 500-999 MET-min/week & $242(3 \%)$ & \\
\hline$\geq 1000 \mathrm{MET}$-min/week & 7064 (83\%) & \\
\hline Health status & & 54 \\
\hline Very good & $1830(22 \%)$ & \\
\hline Good & $5724(68 \%)$ & \\
\hline Fair & 748 (9\%) & \\
\hline Moderate & $94(1 \%)$ & \\
\hline Bad & $21(0 \%)$ & \\
\hline \multicolumn{3}{|l|}{ Disease history } \\
\hline Cardiovascular diseases & 512 & 266 \\
\hline Myocardial infarction & $202(2 \%)$ & 144 \\
\hline Heart failure & $192(2 \%)$ & 180 \\
\hline Stroke & $170(2 \%)$ & 170 \\
\hline Hypertension & $1357(16 \%)$ & 147 \\
\hline Hypercholesterolemia & $1061(13 \%)$ & 166 \\
\hline Diabetes Mellitus & $301(4 \%)$ & 240 \\
\hline Cancer & $664(8 \%)$ & 122 \\
\hline Lung & 11 & \\
\hline Breast & 115 & \\
\hline Intestinal & 61 & \\
\hline Prostate & 90 & \\
\hline Other & 412 & \\
\hline
\end{tabular}




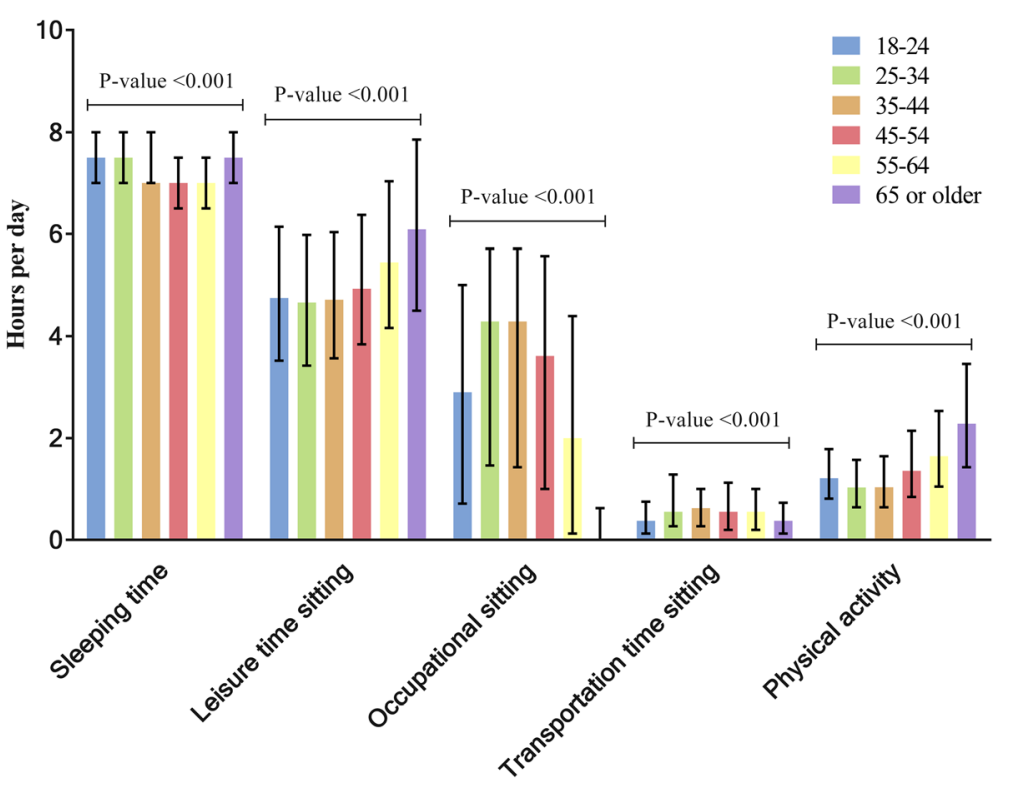

Fig. 1 Time spent on sleeping, leisure time sitting, occupational sitting, transportation time sitting, and physical activity for different age categories $(N=8471)$. The median time spent on different activities is presented by bars and interquartile ranges by lines. Sedentary time during leisure time, occupation, and transportation, physical activity and sleeping time for were significantly different for the age categories $(P$-value Kruskal-Wallis <0.001)

sedentary time for $\geq 8 \mathrm{~h} /$ day; being a former smoker decreased the odds for sitting at work. CVD and CVD risk factors were not associated with sedentary time. On the other hand, cancer was negatively associated with higher levels of occupational sedentary time. Poor health status was associated with higher odds of sedentary time during leisure time.
Results of the imputation analyses were almost similar compared to the complete case analyses. Except for former smoking status and cancer, which were both associated with higher odds of leisure time sitting (Additional file 1: Table S1). In addition, BMI was borderline statistically significant with occupational sedentary time. Results of linear

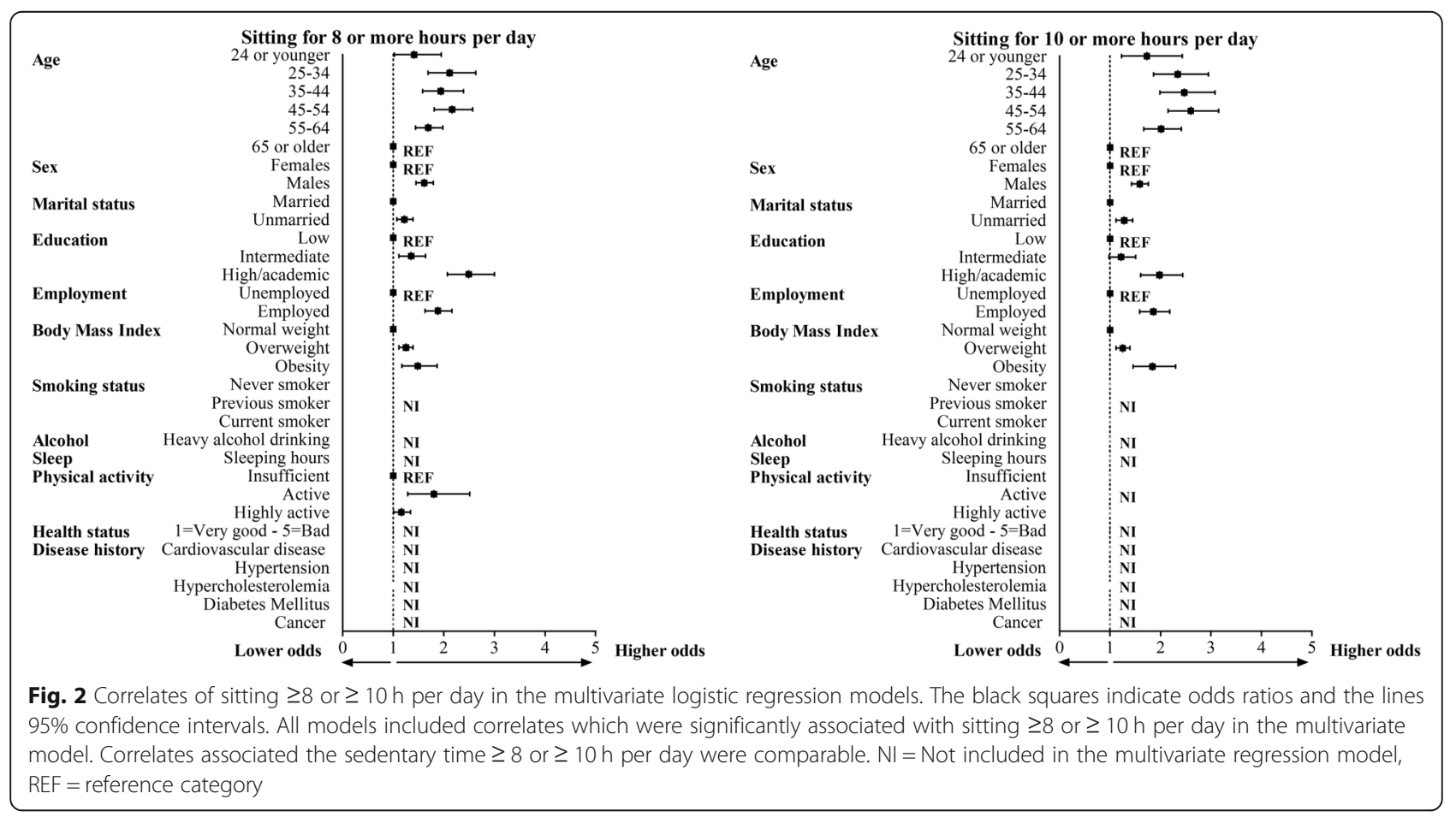



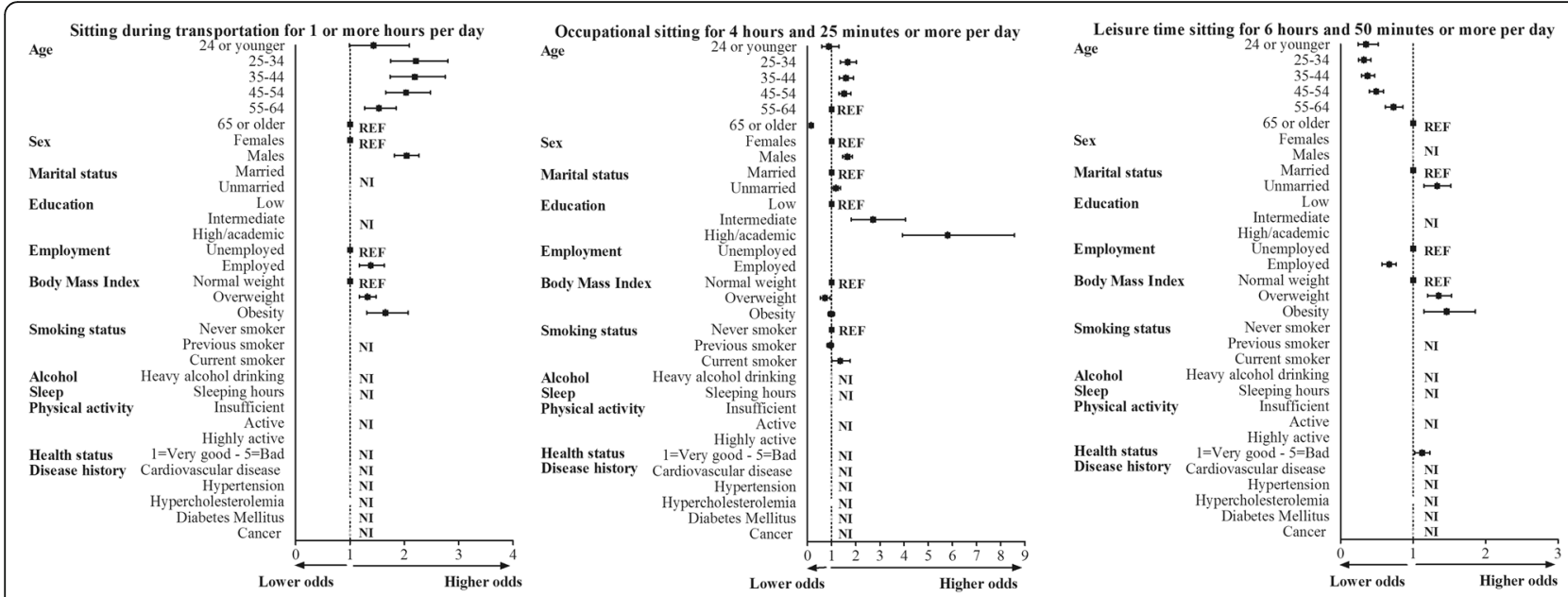

Fig. 3 Correlates of sitting during transportation, occupation and leisure time in the multivariate model. The black squares indicate odds ratios and the lines $95 \%$ confidence intervals. All models included correlates which were significantly associated with sitting during transportation, occupation and leisure time in the multivariate model. Correlates associated the domain specific sedentary time differed within domains. $\mathrm{Nl}=\mathrm{Not}$ included in the multivariate regression model, REF = reference category

regression analyses and the stratified analyses (physically active versus inactive individuals) largely confirmed our main analyses (Additional file 1: Table S2 and S3).

\section{Discussion}

In our cohort we observed a number of new findings. First, a high level of SB was reported $(9.1 \mathrm{~h} /$ day at weekdays; $7.4 \mathrm{~h} /$ day at weekend days), despite $86 \%$ of our population meeting the recommended physical activity dose. Second, we found that the majority of sedentary time was spent during leisure time activities and not at work. Third, younger age, male sex, being unmarried, higher education level, being employed, a higher BMI and higher physical activity levels were independently associated with higher levels of total SB, although this link was not consistently present across all SB domains. Other factors such as smoking status, cancer and health status were associated with specific domains of SB. Our results suggest that, SB is highly prevalent in physically active subjects and that correlates of SB differ across the various domains. Interventions to reduce $\mathrm{SB}$ might benefit from domain-specific targets, whilst the relative importance of these SB domains may differ between groups and/or individuals.

\section{Prevalence of sedentary behavior}

In our study, we found a median total sedentary time of $9.1 \mathrm{~h} /$ day on weekdays and $7.4 \mathrm{~h} /$ day on weekend days. These results highlight that $\mathrm{SB}$ is not only present in the general population, but also highly prevalent in physically active individuals. This observation suggests that public health interventions to reduce sedentary behavior should be developed on a population-wide scale. Interestingly, the amount of sedentary time in our physically active cohort was $\sim 1-4 \mathrm{~h}$ /day higher compared to previous studies [10, 18-21]. This discrepant finding may relate to the observation that Dutch individuals sit more compared to other European countries [18].

Interestingly, most sedentary time was spent during leisure time activities rather than during work. This observation differs from previous findings [21-23]. The difference might be partially explained by the relatively high percentage of older individuals who stopped working (25\%) in our population compared to previous articles [21-23] (all working adults). Another explanation relates to differences in the physical activity levels of the profession, but most individuals in our population were highly educated, who typically perform desk-based office work. Alternatively, occupational sitting time was derived from a single item in the questionnaire, whereas leisure time sitting was calculated from seven items. Hence, study participants may have been reluctant to score a high sedentary time on a single item. Another study using the Sedentary Behavior Questionnaire also found higher levels of leisure time sitting compared to sedentary time at work [14]. Nonetheless, our observations may have important implications for SB interventions in physically active individuals. Since the time spent sedentary during leisure time is significantly higher compared to occupational sitting, workplace interventions for reducing total sedentary time might have limited effects in our population. Possibly, interventions focused on reducing SB during leisure time (e.g. watching TV, eating and drinking, and computer use) may be more relevant, especially since this type of SB counts for $51 \%$ of the total SB time in our population.

\section{Correlates of total and domain-specific sedentary behavior}

Younger age, male sex, being unmarried, higher education level, being employed and a higher BMI were independently associated with higher levels of total SB. SB 
Table 2 Estimates and 95\% Confidence Intervals of the Multivariable Logistic Regression Analysis (Complete Case, N=7648) for the Correlates of Sedentary Behaviour

\begin{tabular}{|c|c|c|c|c|c|c|c|c|c|c|c|c|c|c|c|}
\hline \multirow[b]{2}{*}{ Characteristic } & \multicolumn{3}{|c|}{$\begin{array}{l}\text { Total sedentary } \\
\text { time } \geq 8 \text { h per day }\end{array}$} & \multicolumn{3}{|c|}{$\begin{array}{l}\text { Total sedentary } \\
\text { time } \geq 10 \mathrm{~h} \text { per day }\end{array}$} & \multicolumn{3}{|c|}{$\begin{array}{l}\text { Transportation } \\
\text { sedentary time } \geq 60 \\
\text { min }\end{array}$} & \multicolumn{3}{|c|}{$\begin{array}{l}\text { Occupational sedentary } \\
\text { time } \geq 275 \text { min* }^{*}\end{array}$} & \multicolumn{3}{|c|}{$\begin{array}{l}\text { Leisure sedentary } \\
\text { time } \geq 410 \text { min }\end{array}$} \\
\hline & $\overline{O R}$ & $\begin{array}{l}\text { Lower } \\
95 \% \mathrm{Cl}\end{array}$ & $\begin{array}{l}\text { Upper } \\
95 \% \mathrm{Cl}\end{array}$ & $\overline{O R}$ & $\begin{array}{l}\text { Lower } \\
95 \% \mathrm{Cl}\end{array}$ & $\begin{array}{l}\text { Upper } \\
95 \% \mathrm{Cl}\end{array}$ & $\overline{O R}$ & $\begin{array}{l}\text { Lower } \\
95 \% \mathrm{Cl}\end{array}$ & $\begin{array}{l}\text { Upper } \\
95 \% \mathrm{Cl}\end{array}$ & $\overline{O R}$ & $\begin{array}{l}\text { Lower } \\
95 \% \mathrm{Cl} \\
\end{array}$ & $\begin{array}{l}\text { Upper } \\
95 \% \mathrm{Cl}\end{array}$ & $\overline{O R}$ & $\begin{array}{l}\text { Lower } \\
95 \% \mathrm{Cl}\end{array}$ & $\begin{array}{l}\text { Upper } \\
95 \% \mathrm{Cl}\end{array}$ \\
\hline \multicolumn{16}{|l|}{ Subject } \\
\hline \multicolumn{16}{|l|}{ Age } \\
\hline$\leq 24$ & 1.41 & 1.02 & 1.95 & 1.73 & 1.23 & 2.43 & 1.43 & 0.99 & 2.09 & 0.88 & 0.59 & 1.30 & 0.35 & 0.24 & 0.52 \\
\hline $25-34$ & 2.11 & 1.69 & 2.63 & 2.34 & 1.86 & 2.95 & 2.21 & 1.75 & 2.80 & 1.66 & 1.36 & 2.03 & 0.32 & 0.25 & 0.42 \\
\hline $35-44$ & 1.94 & 1.58 & 2.39 & 2.47 & 1.99 & 3.08 & 2.19 & 1.74 & 2.75 & 1.59 & 1.32 & 1.90 & 0.37 & 0.29 & 0.47 \\
\hline $45-54$ & 2.16 & 1.81 & 2.57 & 2.60 & 2.15 & 3.15 & 2.03 & 1.66 & 2.48 & 1.52 & 1.31 & 1.80 & 0.49 & 0.40 & 0.59 \\
\hline $55-64$ & 1.69 & 1.44 & 1.98 & 2.01 & 1.67 & 2.41 & 1.53 & 1.27 & 1.85 & REF & & & 0.73 & 0.62 & 0.86 \\
\hline$\geq 65$ & REF & & & REF & & & REF & & & 0.15 & 0.09 & 0.24 & REF & & \\
\hline Sex (male) & 1.61 & 1.45 & 1.79 & 1.59 & 1.43 & 1.76 & 2.04 & 1.82 & 2.27 & 1.65 & 1.46 & 1.86 & 1.33 & 1.15 & 1.52 \\
\hline $\begin{array}{l}\text { Marital status } \\
\text { (unmarried) }\end{array}$ & 1.22 & 1.07 & 1.39 & 1.28 & 1.12 & 1.45 & 1.38 & 1.17 & 1.63 & 1.18 & 1.02 & 1.37 & 0.67 & 0.57 & 0.77 \\
\hline \multicolumn{16}{|l|}{ Education } \\
\hline Low & REF & & & REF & & & & & & REF & & & & & \\
\hline Intermediate & 1.35 & 1.11 & 1.64 & 1.22 & 0.98 & 1.51 & & & & 2.71 & 1.82 & 4.05 & & & \\
\hline High/academic & 2.49 & 2.07 & 3.00 & 1.98 & 1.61 & 2.44 & & & & 5.80 & 3.93 & 8.57 & & & \\
\hline Employment (yes) & 1.88 & 1.63 & 2.16 & 1.86 & 1.59 & 2.18 & & & & & & & & & \\
\hline \multicolumn{16}{|l|}{ BMl } \\
\hline Normal weight & REF & & & & & & REF & & & REF & & & REF & & \\
\hline Overweight & 1.25 & 1.11 & 1.39 & & 1.12 & 1.40 & 1.32 & 1.17 & 1.48 & 0.94 & 0.81 & 1.07 & 1.35 & 1.20 & 1.53 \\
\hline Obesity & 1.48 & 1.17 & 1.87 & & 1.46 & 2.30 & 1.65 & 1.31 & 2.07 & 1.35 & 1.02 & 1.77 & 1.46 & 1.15 & 1.86 \\
\hline \multicolumn{16}{|l|}{ Lifestyle } \\
\hline \multicolumn{16}{|l|}{ Smoking status } \\
\hline Never smoker & & & & & & & & & & REF & & & & & \\
\hline Previous smoker & & & & & & & & & & 0.72 & 0.54 & 0.94 & & & \\
\hline Current smoker & & & & & & & & & & 0.98 & 0.86 & 1.12 & & & \\
\hline \multicolumn{16}{|l|}{$\begin{array}{l}\text { Heavy alcohol drinking } \\
\text { (yes) }\end{array}$} \\
\hline \multicolumn{16}{|l|}{ Sleeping hours per day } \\
\hline \multicolumn{16}{|l|}{$\begin{array}{l}\text { Physical activity } \\
\text { guidelines }\end{array}$} \\
\hline$<500 \mathrm{MET}$-min/week & REF & & & & & & & & & & & & & & \\
\hline $\begin{array}{l}\text { 500-999 MET-min/ } \\
\text { week }\end{array}$ & 1.80 & 1.29 & 2.51 & & & & & & & & & & & & \\
\hline $\begin{array}{l}\geq 1000 \text { MET-min/ } \\
\text { week }\end{array}$ & 1.16 & 1.01 & 1.34 & & & & & & & & & & & & \\
\hline $\begin{array}{l}\text { Health status }(1=\text { very } \\
\text { good }-5=\text { poor })\end{array}$ & & & & & & & & & & & & & 1.12 & 1.02 & 1.23 \\
\hline \multicolumn{16}{|l|}{ Disease history } \\
\hline \multicolumn{16}{|l|}{ Cardiovascular diseases } \\
\hline \multicolumn{16}{|l|}{ Hypertension } \\
\hline \multicolumn{16}{|l|}{ Hypercholesterolemia } \\
\hline \multicolumn{16}{|l|}{ Diabetes Mellitus } \\
\hline Cancer & & & & & & & & & & 0.75 & 0.56 & 0.99 & & & \\
\hline
\end{tabular}


correlates identified in the present study align with previous findings $[8,21-26]$, but the direction of the association is different for age, smoking status and physical activity. In our study, age was negatively associated with high levels of sedentary time, which is in contrast to other studies, which found a positive association [20, 27]. A potential explanation for this distinction is that adults in our study, aged 25-64, reported much higher levels of sedentary time (median $9.3 \mathrm{~h} /$ day), compared to other studies (4-8 h/day) [18, 20, 27]. In contrast, our older adult population reported relatively lower levels of sedentary time [28]. A previous study found that retired individuals had higher levels of leisure time SB and physical activity [29], which is comparable with our study results in individuals of $\geq 65$ years old. Former smoking was associated with lower levels of occupational sedentary time and with higher levels of leisure time sitting, compared to individuals who never smoked. In addition, we did not find any association in smokers, which is surprising and may relate to the low number $(n=477,6 \%)$ of smokers in our population. Previous literature has shown that current smoking was associated with TV viewing, but not with total sedentary time [30]. Finally, physical activity was only associated with total sedentary time and not in different domains of SB. A cross-sectional study in 34,555 working adults found that physically active individuals were less sedentary in all domains [23]. The difference between our study and previous findings might be explained by the fact that our participants are mostly active, so maybe the amount of physical activity does not influence domains of SB in an already active population. Another explanation for the discrepant findings of the present study may relate to differences in cohort characteristics. Our cohort includes individuals who received mostly higher education, reporting high levels of physical activity, a low smoking status (6\%), and a high self-reported health status (90\% good to very good), which is different from most general population cohorts [22-24, 31].

Poor health status related to higher volumes of leisure time sitting, which is similar with findings from other studies [31]. However, heath-related issues such as cardiovascular diseases, hypertension, hypercholesterolemia and diabetes mellitus were not associated with sedentary time, which is in contrast to other studies suggesting that patients with cardiovascular diseases and diabetes mellitus are more sedentary compared to healthy controls [32, 33]. Opposite associations were also found for the relationship between cancer and sedentary time [34]. An important difference between our study and previous work is that the majority of the patient population in our study is physically active, might have a healthier lifestyle (only 6\% smokers) and had a good self-reported health status ( $90 \%$ reported good to very good), which is not the case in most general patient populations. This may partially explain the different findings in our population. Still, future studies are needed to confirm our results. Especially studies in large populations investigating combinations of different correlates using multivariable regression models are necessary, because most current studies investigated only small groups of correlates. At least, our results suggest that presence of disease by definition is not automatically related to larger volumes of SB.

In this study, we hypothesized that subject-, lifestyleand health- characteristics relate to SB, but that the magnitude of these associations may differ across SB domains. Indeed, education levels were associated with occupational SB but not with leisure and transportation SB. In addition, the association with age and cancer had a different direction for each domain. These findings indicate that some, but not all, SB correlates are domain specific, suggesting that tailored interventions may be needed to reduce SB across different domains and in specific target groups. Stratified analyses between active and inactive individuals confirmed our main analyses, but some differences were found. For example, discrepant results were found for marital status, BMI, some factors of disease history and lifestyle. Further, in this study we found opposite directions for association between age, current smoking status and physical activity, and high levels of SB compared to other previous mentioned literature. Although the directions were similar for active and inactive individuals in this study, the magnitude was larger in the active individuals. Further studies should determine, whether these differences in associations between active and inactive individuals do exist or whether this due to a lower sample size of inactive individuals.

\section{Strengths and limitations}

The strengths of this study include a large cohort of mostly physically active individuals with a broad range of potential correlates. In addition, we used an extended questionnaire to inquire SB in three domains. We also asked the participants about their sleeping time and their physical activities to get a 24-h overview. However, limitations of our study include self-reported data on SB, physical activity and disease history, which all may cause measurement errors. In addition, occupation SB was measures with only one items, whereas leisure time $\mathrm{SB}$ was measures with seven items. Self-reported SB may be underestimated [35] and selfreported physical activity [36] overestimated compared to objectively measured SB and physical activity. However, due to the sample size of the study it was not feasible to use objective measures for SB and physical activity. In addition, objective measures of SB could not distinguish between different domains in which SB could take place. Future studies are needed to examine correlates of objectively measured sedentary time and patterns of $\mathrm{SB}$, but in order to 
distinguish between domains, objective measures should be combined with subjective measures. Finally, we performed cross-sectional analyses of the associations between subject characteristics and sedentary time. Although the aim of the study was not to examine causation, it could be informative to investigate which correlates are associated with reductions in sedentary time using repeated measurements of SB. This may further improve interventions which aim to reduce sedentary time.

\section{Conclusion}

Our results show that SB is highly prevalent in a physically active population. In addition, younger age, male sex, being unmarried, higher education level, employment and higher BMI are independently associated with higher levels of total SB. Moreover, these factors appear to follow a domainspecific pattern, with most factors showing different relations to SB between occupation- and transportationdomains versus leisure-time. Other factors such as physical activity, smoking status, cancer and health status are associated with specific domains of SB, or only with total sedentary time. These observations indicate that interventions to reduce sedentary time should incorporate correlates for domain-specific SB to enhance the effect size and specifically target the most important domains of SB.

\section{Supplementary information}

Supplementary information accompanies this paper at https://doi.org/10. 1186/s12889-020-8316-6.

Additional file 1: Table S1. Estimates and 95\% Confidence Intervals of the Multivariable Logistic Regression Analysis (Imputation Analyses, $N=$ 8471) for the Correlates of Sedentary Behaviour. Table S2. Estimates and 95\% Confidence Intervals of the Multivariable Linear Regression Analysis (Complete Case, $N=7648$ ) for the Correlates of Sedentary Behaviour. Table S3. Odds Ratios and 95\% Confidence Intervals of the Multivariable Logistic Regression Analysis (Complete Analyses, $N=7648$ ) for the Correlates of Sedentary Behaviour Stratified for Active and Inactive Individuals.

\section{Abbrevations}

BMI: Body Mass Index; CVD: Cardiovascular disease; MET: Metabolic Equivalent of Task; SB: Sedentary Behavior

\section{Acknowledgements}

Not applicable.

\section{Authors' contributions}

EB contributed to the study design, acquisition, analyses and interpretation of the data and drafted the manuscript. TE and DT contributed to the study design and conception, interpretation of the data and revision of the manuscript. $\mathrm{MH}, \mathrm{AV}$ and $\mathrm{DL}$ contributed to the interpretation of the of the data and revision of the manuscript. All authors read and approved the final manuscript.

\section{Funding}

The work of T.M.H.E is supported by the Netherlands Heart Foundation (Senior E-Dekker grant \#2017 T051). This study was performed independent from the Netherlands Heart Foundation. The content is solely the responsibility of the authors and does not necessarily represent the official views of the Netherlands Heart Foundation.
Availability of data and materials

The datasets used and/or analyzed during the current study are available from the corresponding author on reasonable request.

Ethics approval and consent to participate

The study (NL36743.091.11) was approved by The Local Ethics Committee on Research Involving Human Subjects (CMO) of the region Arnhem and Nijmegen, the Netherlands. All participants provided written informed consent.

\section{Consent for publication}

Not applicable.

\section{Competing interests}

The authors declare that they have no competing interests.

\section{Author details}

${ }^{1}$ Department of Physiology, Radboud Institute for Health Sciences, Radboud University Medical Center, P.O. Box 9101, 6500, HB, Nijmegen, The Netherlands. ${ }^{2}$ Research Institute for Sports and Exercise Sciences, Liverpool John Moores University, Liverpool, UK. ${ }^{3}$ Department of Kinesiology, lowa State University, Ames, USA. ${ }^{4}$ Department for Health Evidence, Radboud Institute for Health Sciences, Radboud University Medical Center, Nijmegen The Netherlands.

Received: 28 August 2019 Accepted: 3 February 2020

Published online: 12 February 2020

\section{References}

1. Lee IM, Shiroma EJ, Lobelo F, Puska P, Blair SN, Katzmarzyk PT, et al. Effect of physical inactivity on major non-communicable diseases worldwide: an analysis of burden of disease and life expectancy. Lancet. 2012;380(9838): 219-29.

2. Yates T, Wilmot EG, Davies MJ, Gorely T, Edwardson C, Biddle S, et al. Sedentary behavior: what's in a definition? Am J Prev Med. 2011;40(6):e33-4 author reply e4.

3. Sedentary Behaviour Research N. Letter to the editor: standardized use of the terms "sedentary" and "sedentary behaviours". Appl Physiol Nutr Metab. 2012;37(3):540-2.

4. Tremblay MS, Aubert S, Barnes JD, Saunders TJ, Carson V, Latimer-Cheung $A E$, et al. Sedentary behavior Research network (SBRN) - terminology consensus project process and outcome. Int J Behav Nutr Phys Activity. 2017;14(1):75

5. Biswas A, Oh PI, Faulkner GE, Bajaj RR, Silver MA, Mitchell MS, et al. Sedentary time and its association with risk for disease incidence, mortality, and hospitalization in adults: a systematic review and meta-analysis. Ann Intern Med. 2015;162(2):123-32.

6. Eijsvogels TM, George KP, Thompson PD. Cardiovascular benefits and risks across the physical activity continuum. Curr Opin Cardiol. 2016;31(5):566-71.

7. Owen N, Sugiyama T, Eakin EE, Gardiner PA, Tremblay MS, Sallis JF. Adults' sedentary behavior determinants and interventions. Am J Prev Med. 2011; 41(2):189-96.

8. O'Donoghue G, Perchoux C, Mensah K, Lakerveld J, van der Ploeg H, Bernaards C, et al. A systematic review of correlates of sedentary behaviour in adults aged 18-65 years: a socio-ecological approach. BMC Public Health. 2016;16:163

9. Ekelund U, Steene-Johannessen J, Brown WJ, Fagerland MW, Owen N Powell KE, et al. Does physical activity attenuate, or even eliminate, the detrimental association of sitting time with mortality? A harmonised metaanalysis of data from more than 1 million men and women. Lancet. 2016; 388(10051):1302-10.

10. Endorsed by The Obesity S, Young DR, Hivert MF, Alhassan S, Camhi SM, Ferguson JF, et al. Sedentary behavior and cardiovascular morbidity and mortality: a science advisory from the American Heart Association. Circulation. 2016;134(13):e262-79.

11. National Institute on Alcohol Abuse and Alcoholism. Alcohol use and alcohol use disorders in the United States: Main findings from the 20012002 National Epidemiologic survey on alcohol and related conditions (NESARC). NIH Publication No. 05-5737 2006. 
12. Wendel-Vos GC, Schuit AJ, Saris WH, Kromhout D. Reproducibility and relative validity of the short questionnaire to assess health-enhancing physical activity. J Clin Epidemiol. 2003;56(12):1163-9.

13. Committee PAGA. 2018 Physical activity guidelines advisory Committee scientific report. Washington DC: Department of Health and Human Services; 2018.

14. Rosenberg DE, Norman GJ, Wagner N, Patrick K, Calfas KJ, Sallis JF. Reliability and validity of the Sedentary behavior questionnaire (SBQ) for adults. J Phys Act Health. 2010;7(6):697-705.

15. Ekelund U, Tarp J, Steene-Johannessen J, Hansen BH, Jefferis B, Fagerland MW, et al. Dose-response associations between accelerometry measured physical activity and sedentary time and all cause mortality: systematic review and harmonised meta-analysis. BMJ. 2019;366:14570.

16. Patterson R, McNamara E, Tainio M, de Sa TH, Smith AD, Sharp SJ, et al. Sedentary behaviour and risk of all-cause, cardiovascular and cancer mortality, and incident type 2 diabetes: a systematic review and dose response meta-analysis. Eur J Epidemiol. 2018;33(9):811-29.

17. Pandey A, Salahuddin U, Garg S, Ayers C, Kulinski J, Anand V, et al. Continuous dose-response association between Sedentary time and risk for cardiovascular disease: a meta-analysis. JAMA Cardiol. 2016;1(5):575-83.

18. Loyen A, van der Ploeg HP, Bauman A, Brug J, Lakerveld J. European sitting championship: prevalence and correlates of self-reported sitting time in the 28 European Union member states. PLoS One. 2016;11(3):e0149320.

19. Schuna JM Jr, Johnson WD, Tudor-Locke C. Adult self-reported and objectively monitored physical activity and sedentary behavior: NHANES 2005-2006. Int J Behav Nutr Phys Activity. 2013;10:126.

20. Matthews CE, Chen KY, Freedson PS, Buchowski MS, Beech BM, Pate RR, et al. Amount of time spent in sedentary behaviors in the United States, 2003-2004. Am J Epidemiol. 2008;167(7):875-81.

21. Bennie JA, Pedisic Z, Timperio A, Crawford D, Dunstan D, Bauman A, et al. Total and domain-specific sitting time among employees in desk-based work settings in Australia. Aust N Z J Public Health. 2015;39(3):237-42.

22. Chau JY, van der Ploeg HP, Merom D, Chey T, Bauman AE. Cross-sectional associations between occupational and leisure-time sitting, physical activity and obesity in working adults. Prev Med. 2012;54(3-4):195-200.

23. Saidj M, Menai M, Charreire H, Weber C, Enaux C, Aadahl M, et al. Descriptive study of sedentary behaviours in 35,444 French working adults: cross-sectional findings from the ACTI-cites study. BMC Public Health. 2015;15:379.

24. Salmon J, Owen N, Crawford D, Bauman A, Sallis JF. Physical activity and sedentary behavior: a population-based study of barriers, enjoyment, and preference. Health Psychol. 2003;22(2):178-88.

25. Prince SA, Reed JL, McFetridge C, Tremblay MS, Reid RD. Correlates of sedentary behaviour in adults: a systematic review. Obesity Rev. 2017;18(8): 915-35.

26. Proper Kl, Cerin E, Brown WJ, Owen N. Sitting time and socio-economic differences in overweight and obesity. Int J Obes. 2007;31(1):169-76.

27. Clark BK, Healy GN, Winkler EA, Gardiner PA, Sugiyama T, Dunstan DW, et al. Relationship of television time with accelerometer-derived sedentary time: NHANES. Med Sci Sports Exerc. 2011;43(5):822-8.

28. Stamatakis E, Davis M, Stathi A, Hamer M. Associations between multiple indicators of objectively-measured and self-reported sedentary behaviour and cardiometabolic risk in older adults. Prev Med. 2012;54(1):82-7.

29. Menai M, Fezeu L, Charreire H, Kesse-Guyot E, Touvier M, Simon C, et al. Changes in sedentary behaviours and associations with physical activity through retirement: a 6-year longitudinal study. PLoS One. 2014;9(9): e106850.

30. Rhodes RE, Mark RS, Temmel CP. Adult sedentary behavior: a systematic review. Am J Prev Med. 2012;42(3):e3-28.

31. Bennie JA, Chau JY, van der Ploeg HP, Stamatakis E, Do A, Bauman A. The prevalence and correlates of sitting in European adults - a comparison of 32 Eurobarometer-participating countries. Int J Behav Nutr Phys Act. 2013;10:107.

32. Evenson KR, Butler EN, Rosamond WD. Prevalence of physical activity and sedentary behavior among adults with cardiovascular disease in the United States. J Cardiopulmonary Rehab Prev. 2014;34(6):406-19.

33. Wilmot EG, Edwardson CL, Achana FA, Davies MJ, Gorely T, Gray LJ, et al. Sedentary time in adults and the association with diabetes, cardiovascular disease and death: systematic review and meta-analysis. Diabetologia. 2012; 55(11):2895-905

34. Kim RB, Phillips A, Herrick K, Helou M, Rafie C, Anscher MS, et al. Physical activity and sedentary behavior of cancer survivors and non-cancer individuals: results from a national survey. PLoS One. 2013;8(3):e57598.
35. Stamatakis E, Hamer M, Tilling K, Lawlor DA. Sedentary time in relation to cardio-metabolic risk factors: differential associations for self-report vs accelerometry in working age adults. Int J Epidemiol. 2012;41(5):1328-37.

36. Adams SA, Matthews CE, Ebbeling CB, Moore CG, Cunningham JE, Fulton J, et al. The effect of social desirability and social approval on self-reports of physical activity. Am J Epidemiol. 2005;161(4):389-98.

\section{Publisher's Note}

Springer Nature remains neutral with regard to jurisdictional claims in published maps and institutional affiliations.
Ready to submit your research? Choose BMC and benefit from:

- fast, convenient online submission

- thorough peer review by experienced researchers in your field

- rapid publication on acceptance

- support for research data, including large and complex data types

- gold Open Access which fosters wider collaboration and increased citations

- maximum visibility for your research: over $100 \mathrm{M}$ website views per year

At BMC, research is always in progress.

Learn more biomedcentral.com/submissions 